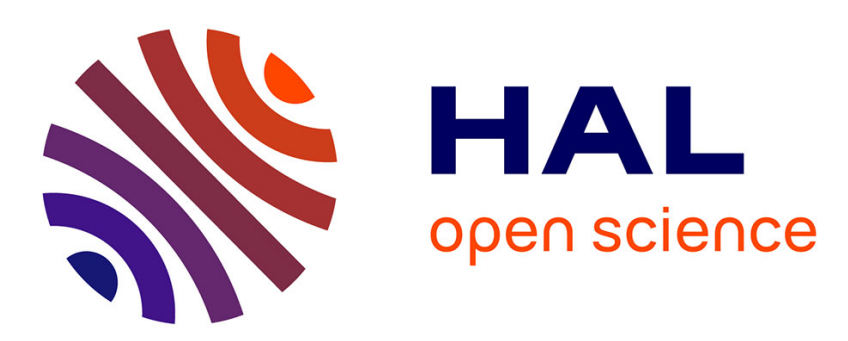

\title{
Thermal inertia variations from gully and mass-wasting activity in Gasa crater, Mars
}

Tanya N Harrison, Livio Tornabene, Gordon Osinski, Susan J Conway

\section{To cite this version:}

Tanya N Harrison, Livio Tornabene, Gordon Osinski, Susan J Conway. Thermal inertia variations from gully and mass-wasting activity in Gasa crater, Mars. The Geological Society, London, Special Publications, 2019, 467 (1), pp.199-210. 10.1144/SP467.8 . hal-02270629

\section{HAL Id: hal-02270629 \\ https://hal.science/hal-02270629}

Submitted on 8 Jan 2021

HAL is a multi-disciplinary open access archive for the deposit and dissemination of scientific research documents, whether they are published or not. The documents may come from teaching and research institutions in France or abroad, or from public or private research centers.
L'archive ouverte pluridisciplinaire HAL, est destinée au dépôt et à la diffusion de documents scientifiques de niveau recherche, publiés ou non, émanant des établissements d'enseignement et de recherche français ou étrangers, des laboratoires publics ou privés. 


\section{Thermal inertia variations from recent gully and mass wasting activity in Gasa}

3 Tanya N. Harrison ${ }^{1 \dagger}$, Livio L. Tornabene ${ }^{1}$, Gordon R. Osinski ${ }^{1,2}$, and Susan J. Conway ${ }^{3}$

${ }^{I}$ Centre for Planetary Science and Exploration, Department of Earth Sciences, University of Western Ontario

$5 \quad{ }^{2}$ Department of Physics and Astronomy, University of Western Ontario

$6{ }^{3}$ Laboratoire de Planétologie et Géodynamique, Nantes, France.

$7 \quad$ Current affiliation: NewSpace Initiative, Arizona State University, Tempe, AZ, USA

\section{1. Introduction}

10 Gullies are incised channel features with source alcoves and depositional fans

11 found on slopes in the middle and high latitudes of Mars [Malin and Edgett, 2000]. Their

12 morphology is highly suggestive of liquid water having been involved in their initial

13 formation. This includes features such as banked, sinuous, and terraced channels,

14 superelevation of gully deposits, and terminal deposits travelling across slopes much

15 lower than the angle of repose for dry material [e.g., Malin and Edgett, 2000; Heldmann

16 and Mellon, 2004; Malin et al., 2006; McEwen et al., 2007], although dry and frost-

17 related processes have also been proposed [e.g., Treiman, 2003; Hugenholtz, 2008;

18 Cedillo-Flores et al., 2011; Dundas et al., 2012, 2015]. They also appear to be

19 geologically youthful, typically lacking craters and superposing recent aeolian features

20 such as transverse aeolian ridges [e.g., Malin and Edgett, 2000; Reiss et al., 2004; Schon

21 et al., 2009]. The unexpected observation of new light-toned flows in two pre-existing

22 gully channels with the Mars Global Surveyor (MGS) narrow angle Mars Orbiter Camera 
23 (MOC NA) [Malin et al., 2006] led to monitoring efforts to look for gully activity in an

24 attempt to constrain how gullies on Mars may have formed, and how they are evolving

25 today.

26 Carrying on the monitoring efforts of MOC NA, the Mars Reconnaissance Orbiter

27 (MRO) Context Camera (CTX) [Malin et al., 2007] routinely monitors 617 locations

28 across both hemispheres at a pixel scale of $6 \mathrm{~m}$ for present-day gully activity [Harrison et

29 al., 2009]. The High-Resolution Imaging Science Experiment (HiRISE) aboard MRO

30 [McEwen et al., 2007] monitors approximately 500 of these locations at a pixel scale of

$31 \sim 0.25-1 \mathrm{~m}[$ Dundas et al., 2016]. Thus far, present-day activity ranging from the

32 movement of boulders [Dundas et al., 2015] to the deposition of material on aprons and

33 incision of new small channel segments [e.g., Malin et al., 2006; Harrison et al., 2009;

34 Dundas et al., 2010] has been observed in 38 separate locations over the past decade. Of

35 these, Gasa Crater has been the most active site observed on Mars to date, making it of

36 particular interest for studying the process(es) behind gully formation and activity. In this

37 study, we investigate whether differences in thermal inertia across different segments of

38 gully systems, combined with morphological and colour observations with HiRISE, can

39 provide some constraints of the physical characteristics associated with recent activity

40 within gullies in Gasa. We also investigate thermophysical differences between slopes in

41 Gasa dominated by gully activity compared to those predominantly modified by dry mass

42 wasting processes. Thermal inertia can be used to model the grain size and/or induration

43 of the upper ( $\sim 1$ to $10 \mathrm{~cm})$ of surface materials [e.g., Fergason et al., 2006]; as such, this

44 dataset can help us to better understand the mass movement processes occurring on the

45 slopes within Gasa Crater. 


\section{2. Setting and Previous Work on Gasa Crater}

Gasa Crater is a $\sim 7 \mathrm{~km}$ impact crater centred at $35.7^{\circ} \mathrm{S}, 129.4^{\circ} \mathrm{E}$ (Figure 1 ), which

49 lies within the floor deposits of the older, infilled and degraded Cilaos impact crater $(\sim 19$

$50 \mathrm{~km}$-diameter). Despite extensive gully activity on its northern wall, Gasa appears

51 morphologically well preserved [e.g., Tornabene et al., 2006, 2012] consistent with a

52 young modeled age. Crater counts on the continuous ejecta blanket of Gasa yield a crater

53 retention age of $0.6-2.4 \mathrm{Ma}$, with a best-fit age of $1.25 \mathrm{Ma}$, possibly coinciding with the

54 last glacial maximum on Mars [Schon et al., 2009]. Relatively unmodified secondary

55 craters and a lack of evidence for pasted-on deposits on the pole-facing wall suggest that

56 Gasa Crater formed after the last major episode of latitude-dependent mantle

57 emplacement in the southern mid-latitudes [Schon et al., 2009; Schon and Head, 2012].

58 The floor of Gasa hosts pitted deposits of the type extensively documented by Tornabene

59 et al. [2012]. Such deposits are thought to represent primary crater-related deposits,

60 which are interpreted to form from the interaction of impact melt with volatiles

61 originating from the target [Boyce et al., 2012; Tornabene et al., 2012]. The preservation

62 of these deposits, especially atop the ejecta blanket, support the interpretation that Gasa is

63 not only geologically youthful, but well presereved.

64 Cilaos Crater, within which Gasa Crater sits, hosts gullies on its pole-facing walls.

65 These gullies formed within the pasted-on mantle emplaced before the formation of Gasa.

66 However, in some places the Cialos gullies appear to superpose Gasa ejecta, suggesting

67 that gully activity in the region occurred both before and after the formation of Gasa [i.e., 
68 Schon and Head, 2012]. The pole-facing walls of Gasa host many gullies, with

69 morphologies suggesting fluidized flows (such as debris flows) may have played a role in

70 their formation [Kolb et al., 2010; Lanza et al., 2010; Conway et al., 2011]. The gullies

71 within Gasa incise into the underlying bedrock [Okubo et al., 2011], unlike many other

72 gullies on Mars that are observed within "pasted-on" crater wall mantling deposits [i.e.,

73 Christensen, 2003; Dickson et al., 2015]. Features interpreted as crown fractures, which

74 represent extensional strains from downslope movement of rock in terrestrial mass

75 movements, are observed in association with gully alcoves on the northeast wall of the

76 crater, but not with the north/northwestern wall gullies. This may imply that the

77 northeastern wall is the least stable in the crater [Okubo et al., 2011]. The equator-facing

78 crater walls are steeper (Figure 1B) and display features with morphologies consistent

79 with dry mass wasting processes observed within other well-preserved (non-gullied)

80 craters similar in size to Gasa [e.g., Tornabene et al., 2016]. Gasa Crater has the highest

81 asymmetry in backweathering rates of its pole-facing vs. equator-facing walls (factor of

$82 \sim 60)$ of all craters analyzed by de Haas et al. [2013], suggesting its gullied pole-facing

83 wall is eroding at a much faster rate than the non-gullied equator-facing wall.

85 2. Methods

86 Thermal inertia is defined as:

$$
I=(k \rho c)^{1 / 2}
$$

88 where $\mathrm{k}$ is the thermal conductivity, $\rho$ is the bulk density, and $\mathrm{c}$ is the specific heat

89 capacity of the surface material. Units are in $\mathrm{J} \mathrm{m}^{-2} \mathrm{~K}^{-1} \mathrm{~s}^{-1 / 2}$, herein shortened to "thermal 
90 inertia units" (TIU). On Mars, thermal inertia is most strongly controlled by the thermal

91 conductivity of a material, which ranges over 3-4 orders of magnitude, while specific

92 heat capacity and density only vary by a factor of $\sim 3$ for rocks and soils [e.g., Wechsler

93 and Glaser, 1965; Neugebauer et al., 1971; Wechsler et al., 1972; Presley and

94 Christensen, 1997b]. As such, thermal inertia is strongly controlled by the particle size of

95 a material, with bulk conductivity varying as a function of the solid, radiative, and

96 conductivity of interstitial gas. Solid and gas conductivity play the largest role under

97 martian conditions [Wechsler et al., 1972], predominantly controlled by the relationship

98 between the particle size and the pore size relative to the mean-free path of a gas ( $\sim 5 \mu \mathrm{m}$

99 at martian surface pressures). When grain sizes are small enough that the pore size is

100 about the same or smaller than the mean free gas path, heat transfer becomes inefficient

101 due to a lower frequency of collisions between gas molecules and grains in the material.

102 Thermal conductivity of fine-grained materials is also lowered due to the higher number

103 of grain-to-grain contacts per unit length [Jakosky, 1986; Presley and Christensen,

$1041997 \mathrm{a}]$. For grains larger than $\sim 5 \mu \mathrm{m}$, thermal inertia is controlled by the size of a particle

105 relative to the diurnal thermal skin depth $(\sim 1 \mathrm{~cm}$ for sand and $\sim 10 \mathrm{~cm}$ for rock) [e.g.,

106 Hardgrove et al., 2009]. This results in fine-grained, unconsolidated materials having

107 lower thermal inertia values than coarse-grained and/or well-indurated (cemented)

108 materials, although it is important to note that thermal inertia values alone are non-unique

109 [e.g., Fergason et al., 2006 and references therein]. High resolution images provide

110 additional insight on the texture and grain size of thermal inertia units.

111 Quantitative thermal inertia (TI) at $100 \mathrm{~m}$ per pixel was measured on standard

112 data products calculated from Thermal Emission Imaging System (THEMIS) night-time 
113 IR data [Christensen et al., 2004] with an overall accuracy of $\sim 20 \%$, precision of $10-15 \%$.

114 THEMIS TI values are generally consistent with MGS Thermal Emission Spectrometer

115 (TES) and the Mars Exploration Rovers mini-TES derived thermal inertia values

116 [Fergason et al., 2006]. We analysed the 32-bit $100 \mathrm{~m} /$ pixel THEMIS thermal inertia

117 images [Fergason et al., 2006; Christensen et al., 2013] using the map sampling function

118 in the Java Mission-planning and Analysis for Remote Sensing (JMARS) software

119 package [Christensen et al., 2009]. Gasa Crater was chosen both based on the size of its

120 gully aprons, and because it is one of the few sites on Mars where present-day gully

121 activity has been observed in multiple locations within the same crater over several Mars

122 years [Dundas et al., 2010, 2015]. Gully fan segments were mapped morphologically

123 using HiRISE images ESP_014081_1440 and ESP_039531_1440 for complete clear-

124 atmopshere, low shadow, and low emission angle $\left(<3^{\circ}\right)$ coverage of the crater, with the

125 HiRISE and THEMIS TI datasets each manually georeferenced to the THEMIS daytime

126 IR 100 m global map (version 12) in JMARS. The HiRISE images were extremely

127 contrast stretched during mapping to enhance details within the gully fans. Additional

128 map creation was completed using ArcMap 10.2.

129 Due to differences in calibration between images and slope effects on absolute

130 THEMIS thermal inertia values [Fergason et al., 2006], we focus this work on the

131 relative differences in thermal inertia between individual gully aprons and lobes within

132 aprons using a single THEMIS TI strips covering Gasa (image ID I09926012, quality

133 rating 5, acquired on 10 March 2004 at $\mathrm{L}_{\mathrm{s}} 2.48^{\circ}$ — near the start of southern autumn when

134 surface frost has not been deposited at these latitudes). Only images with a quality rating

135 of 5 or higher ( 7 being the highest possible rating), assigned by the THEMIS team, were 
136 considered for use. Polygons were drawn covering portions of gully aprons,

137 distinguishing between the youngest (stratigraphically topmost) apron deposits and the

138 underlying older apron deposits (Figure 2). These polygons were drawn to intentionally

139 subsample the apron deposits due to the difference in resolution between THEMIS TI and

140 HiRISE in order to minimize sampling from surrounding pixels covering other aprons.

141 Using the map sampling feature in JMARS, the thermal inertia values for pixels within

142 each polygon were extracted. This map sampling function works such that if a pixel is

143 more than $50 \%$ contained within the sampling polygon, its value is included in

144 calculations; otherwise, the pixel is not counted [Scott Dickenshied, personal

145 communication $\left.^{1}\right]$.

147 3. Results

1483.1 General thermal inertia conditions within Gasa Crater

149 The materials within Gasa exhibit a wide range of thermal inertia values (Figure

150 3). The lowest values, averaging $\sim 312$ TIU, correspond with what is likely to be

151 unconsolidated fine-grained deposits that have settled atop of - but not infilling or

152 obscuring — pitted materials on the crater floor. The highest TI values correspond with

153 bedrock exposures in the crater walls, particularly along the southwestern (non-gullied)

154 wall and within the gully alcoves of the pole-facing walls. Thermal inertia values of gully

155 aprons on the pole-facing wall have average thermal inertias $\sim 60-75$ TIU lower than the

156 talus on the equator-facing wall (Figure 4; Table 1), suggesting the gully aprons are

\footnotetext{
${ }^{1}$ Scott Dickenshied a Scientific Software Designer at ASU and one of the lead developers for JMARS.
} 
157 dominated by finer-grained material than the talus slopes. The gullied walls as a whole

158 have a lower average thermal inertia than the non-gullied walls, consistent with

159 observations by Lanza et al [2011] regarding differences in thermal inertia values of

160 gullied vs. non-gullied crater walls. However, the alcoves of gullied and non-gullied

161 walls have similar high TI values, generally greater than 460 TIU. Moderate TI values

162 correspond with coarse-grained, unconsolidated talus on the equator-facing walls,

163 consistent with preliminary morphologic and thermophysical mapping results by

164 Tornabene et al. [2016] in non-gullied well-preserved craters. HiRISE IRB colour

165 imaging of Gasa supports this interpretation. In HiRISE IRB images, yellows correspond

166 to surfaces that are richer in ferric-bearing materials (in many cases due to coatings or the

167 presence of fine-grained martian "dust") while blues correspond to ferrous-bearing

168 materials [Delamere et al., 2010]. The gullied walls of Gasa are generally yellower in the

169 HiRISE IRB than the non-gullied walls (Figure 6), suggesting the gullied walls are

170 potentially more dust-covered than the non-gullied talus slopes.

171

1723.2 Thermal inertia and recent gully activity

173 Analysis of 66 individual gully fan segments show that in Gasa, the average

174 thermal inertia values of the youngest apron deposits are generally $\sim 20-40$ TIU higher

175 than the older underlying/surrounding deposits (Figures 4B-5). Present-day gully activity

176 has been documented in gullies \#10, 12, and 19 (as labelled in Figure 3) by Dundas et al.

177 [2010, 2012, 2015]. All three of these have aprons with areas of concentrations of higher

178 TI (yellow patches in Figure 3) relative to other fans/fan segments, although they are not 
179 the only gullies with high TI fan segments. This could suggest that additional gullies

180 within Gasa have been recently active, but not within the period of monitoring by CTX

181 and HiRISE. It should be noted that the THEMIS image used in this study was acquired

182 in 2004, before the changes documented by Dundas et al. [2010, 2012, 2015] occurred;

183 therefore, we are not seeing the most recent changes that have occurred within Gasa with

184 this THEMIS dataset.

186 4. Discussion

187 The observation of lower thermal inertia values for older fan deposits in martian 188 gullies, combined with HiRISE IRB colour results, suggests that martian gully deposits

189 decrease in thermal inertia over time due to deposition of atmospheric dust. Thermal

190 mapping of alluvial fans in Death Valley by Hardgrove et al. [2009, 2010] found that

191 older fan deposits had a higher thermal inertia than younger deposits, as their fine-

192 grained component had been eroded away by aeolian (i.e., deflation) and fluvial

193 processes. On Mars, the opposite effect appears to be the case, as the rate of dust

194 deposition greatly exceeds the rate of deflation. This is consistent with estimates based on

195 in situ surface investigations. The Mars Exploration Rovers [Kinch et al., 2015] and

196 Phoenix [Drube et al., 2010] found an average dust deposition rate of $0.02-0.06 \mu \mathrm{m}$ per

197 sol, whereas deflation rates calculated from the Pathfinder [Golombek and Bridges, 2000]

198 and the Mars Exploration Rovers [Golombek et al., 2006, 2014] are only $\sim 0.1 \mathrm{~nm} / \mathrm{Myr}$ in 199 the Amazonian. 
Another process likely acting to reduce the thermal inertia of martian gully fan

201 lobes is the rapid breakdown of fan material. Denudation of inactive fans in both

202 terrestrial hot-arid and cold polar desert environments results in the creation of a smooth

203 desert pavement on fan surfaces as weathering and erosion proceed [e.g., Matmon et al.,

204 2006; Frankel and Dolan, 2007; de Haas et al., 2013]. de Haas et al. [2013] calculated

205 denudation rates in the Amazonian of $0.89 \mathrm{~m} / \mathrm{Ma}$, which would result in subduing small-

206 scale morphology on gully fans on timescales of $<1$ Ma. This smoothing effect would be

207 expected to lead to a lowering of thermal inertia values as larger grains in fan deposits

208 break down. On Earth, debris appears to break down more quickly in cold polar desert

209 (periglacial) environments relative to hot-arid deserts due to the action of snow

210 avalanches, permafrost, and freeze-thaw cycles [de Haas et al., 2014, 2015]—decades

211 [e.g., André, 1990, 1995; Luckman, 1992] as opposed to thousands or hundreds of

212 thousands of years [Matmon et al., 2006; Frankel and Dolan, 2007]. Recurring snow

213 avalanches can erode debris flow levees on Earth in as little as $\sim 20-40$ years, whereas

214 debris flow levees in areas that do not experience snow avalanches can be preserved for

215 hundreds to thousands of years [e.g., André, 1990, 1995; Luckman, 1992]. A similar

216 process could potentially occur on Mars with dust avalanches, although slope streaks

217 (thought to represent dust avalanches) are not typically observed in conjunction with

218 martian gullies. Rapid breakdown of gully deposits may also explain why characteristic

219 features of debris flows (i.e., levees) are only observed in a few martian gullies [e.g., Levy

220 et al., 2010] despite morphological parameters suggesting debris flows as a likely

221 candidate process for gully formation [e.g., Lanza et al., 2010; Conway et al., 2011,

222 2015; de Haas et al., 2014]. 


\section{5. Implications and Future Work}

225 Gasa Crater exhibits clear variations in thermal inertia across its walls, controlled

226 by the material properties and the types of dominant mass movement processes occurring

227 on each wall. The youthful gully fan lobes display thermal inertia values $\sim 20-40$ TIU

228 higher than adjacent older eroded and dust-covered lobes. The talus aprons from mass

229 wasting in Gasa have thermal inertia values $\sim 60-80$ TIU higher than gully aprons. The

230 results of this study thus suggest that repeated THEMIS day/night IR imaging

231 coordinated with MRO observations could be used for surface change detection. In the

232 case of gullies large enough to be resolved in the THEMIS IR, acquiring at least 1-2

233 images (in order to ensure at least 1 of acceptable quality is returned) at the beginning

234 and end of each season in both hemispheres would be ideal as gully activity appears to be

235 seasonally constrained to autumn through early spring [e.g., Harrison et al., 2009;

236 Diniega et al., 2010; Dundas et al., 2010, 2012, 2015]. Analysis of thermal inertia

237 differences could aid in selecting or refining sites for monitoring by CTX and HiRISE,

238 and the $\sim 5 \mathrm{~m} /$ pixel Colour and Stereo Surface Imaging System (CaSSIS) aboard the

239 European Space Agency's ExoMars Trace Gas Orbiter [Thomas et al., 2014].

240 Additionally, the thermal imaging of Hardgrove et al. [2009] revealed structure within

241 alluvial fans in Death Valley not distinguishable in visible images. This, combined with

242 the results of our study, may make a case for sending a higher-resolution thermal imager

243 to Mars on a future orbiter, as it could prove to be a valuable asset to study the structure

244 of gullies and deltas/alluvial fans, all of which are found in abundance on the planet. 


\section{Acknowledgements}

247 T. N. Harrison acknowledges funding for this project from the Vanier Canada

248 Graduate Scholarship and the Amelia Earhart Fellowship. Feedback from Colin Dundas,

249 Phil Stooke, and Catherine Neish helped to improve this manuscript. 


\section{References}

252 André, M.-F. (1990), Frequency of debris flows and slush avalanches in Spitsbergen: a 253 tentative evaluation from lichenometry, Polish Polar Res., 11(3-4), 345-363.

254 André, M.-F. (1995), Holocene climate fluctuations and geomorphic impact of extreme 255 events in Svalbard, Geogr. Ann. Ser. A-PHYSICAL Geogr., 77(4), 241-250.

256 Boyce, J. M., L. Wilson, P. J. Mouginis-Mark, C. W. Hamilton, and L. L. Tornabene 257 (2012), Origin of small pits in martian impact craters, Icarus, 221(1), 262-275, $258 \quad$ doi:10.1016/j.icarus.2012.07.027.

259 Cedillo-Flores, Y., A. H. Treiman, J. Lasue, and S. M. Clifford (2011), CO2 gas

260 fluidization in the initiation and formation of Martian polar gullies, Geophys. Res. 261 Lett., 38(L21202), doi:10.1029/2011GL049403.

262 Christensen, P. R. (2003), Formation of recent martian gullies through melting of 263 extensive water-rich snow deposits, Nature, 422(6927), 45-48, 264 doi:10.1038/nature01436.

265 Christensen, P. R. et al. (2004), The Thermal Emission Imaging System (THEMIS) for 266 the Mars 2001 Odyssey Mission, Space Sci. Rev., 110, 85-130, 267 doi:10.1023/B:SPAC.0000021008.16305.94.

268 Christensen, P. R., E. Engle, S. Anwar, S. Dickenshied, D. Noss, N. Gorelick, and M. 269 Weiss-Malik (2009), JMARS - A Planetary GIS, Am. Geophys. Union, Fall Meet. $270 \quad$ 2009, abstract \#IN22A-06.

271 Christensen, P. R., R. L. Fergason, C. S. Edwards, and J. Hill (2013), THEMIS-Derived 
274 Conway, S. J., M. R. Balme, J. B. Murray, M. C. Towner, C. H. Okubo, and P. M.

275 Grindrod (2011), The indication of Martian gully formation processes by slope-area 276 analysis, Geol. Soc. London, Spec. Publ., 356(1), 171-201, doi:10.1144/sp356.10.

277 Conway, S. J., M. R. Balme, M. A. Kreslavsky, J. B. Murray, and M. C. Towner (2015), 278 The comparison of topographic long profiles of gullies on Earth to gullies on Mars: 279 A signal of water on Mars, Icarus, 253, 189-204, doi:10.1016/j.icarus.2015.03.009.

280 Delamere, W. A. et al. (2010), Color imaging of Mars by the High Resolution Imaging 281 Science Experiment (HiRISE), Icarus, 205(1), 38-52, 282 doi:10.1016/j.icarus.2009.03.012.

283 Dickson, J. L., J. W. Head, T. A. Goudge, and L. Barbieri (2015), Recent climate cycles 284 on Mars: Stratigraphic relationships between multiple generations of gullies and the latitude dependent mantle, Icarus, 252, 83-94, doi:10.1016/j.icarus.2014.12.035.

286 Diniega, S., S. Byrne, N. T. Bridges, C. M. Dundas, and A. S. McEwen (2010), 287 Seasonality of present-day Martian dune-gully activity, Geology, 38(11), 1047-1050, 288 doi:10.1130/G31287.1.

289 Drube, L. et al. (2010), Magnetic and optical properties of airborne dust and settling rates 290 of dust at the Phoenix landing site, J. Geophys. Res., 115, E00E23, 291 doi:10.1029/2009JE003419.

292 Dundas, C. M., A. S. McEwen, S. Diniega, S. Byrne, and S. Martinez-Alonso (2010), 293 New and recent gully activity on Mars as seen by HiRISE, Geophys. Res. Lett., 
295 Dundas, C. M., S. Diniega, C. J. Hansen, S. Byrne, and A. S. McEwen (2012), Seasonal 296 activity and morphological changes in martian gullies, Icarus, 220(1), 124-143, 297 doi:10.1016/j.icarus.2012.04.005.

298 Dundas, C. M., S. Diniega, and A. S. McEwen (2015), Long-term monitoring of martian 299 gully formation and evolution with MRO/HiRISE, Icarus, 251, 244-263, $300 \quad$ doi:10.1016/j.icarus.2014.05.013.

301 Dundas, C. M., S. Diniega, A. S. McEwen, C. J. Hansen, and S. Byrne (2016), 302 Monitoring martian gullies: Implications for formation and evolution, in Martian $303 \quad$ Gullies and Their Earth Analogues, London, United Kingdom.

304 Fergason, R. L., P. R. Christensen, and H. H. Kieffer (2006), High-resolution thermal 305 inertia derived from the Thermal Emission Imaging System (THEMIS): Thermal 306 model and applications, J. Geophys. Res. E Planets, 111(12), 1-22, 307 doi:10.1029/2006JE002735.

308 Frankel, K. L., and J. F. Dolan (2007), Characterizing arid region alluvial fan surface 309 roughness with airborne laser swath mapping digital topographic data, J. Geophys. $310 \quad$ Res., 112, F02025, doi:10.1029/2006JF000644.

311 Golombek, M. P., and N. T. Bridges (2000), Erosion rates on Mars and implications for 312 climate change: Constraints from the Pathfinder landing site, J. Geophys. Res., 105, $313 \quad 1841-1853$.

314 Golombek, M. P. et al. (2006), Erosion rates at the Mars Exploration Rover landing sites 315 and long-term climate change on Mars, J. Geophys. Res., 111(E12), 
317 Golombek, M. P., N. H. Warner, V. Ganti, M. P. Lamb, T. J. Parker, R. L. Fergason, and

318 R. Sullivan (2014), Small crater modification on Meridiani Planum and implications

319 for erosion rates and climate change on Mars, J. Geophys. Res., 119(12), 2522-2547, 320 doi:10.1002/2014JE004658.

321 de Haas, T., E. Hauber, and M. G. Kleinhans (2013), Local late Amazonian boulder 322 breakdown and denudation rate on Mars, Geophys. Res. Lett., 40(14), 3527-3531, 323 doi:10.1002/grl.50726.

324 de Haas, T., D. Ventra, P. E. Carbonneau, and M. G. Kleinhans (2014), Geomorphology

325 Debris- fl ow dominance of alluvial fans masked by runoff reworking and 326 weathering, Geomorphology, 217, 165-181, doi:10.1016/j.geomorph.2014.04.028.

327 de Haas, T., M. G. Kleinhans, P. E. Carbonneau, L. Rubensdotter, and E. Hauber (2015), 328 Surface morphology of fans in the high-Arctic periglacial environment of Svalbard:

329 Controls and processes, Earth Sci. Rev., 146, 163-182,

330 doi:10.1016/j.earscirev.2015.04.004.

331 Hardgrove, C., J. Moersch, and S. Whisner (2009), Thermal imaging of alluvial fans: A 332 new technique for remote classification of sedimentary features, Earth Planet. Sci. 333 Lett., 285(1-2), 124-130, doi:10.1016/j.eps1.2009.06.004.

334 Hardgrove, C., J. Moersch, and S. Whisner (2010), Thermal imaging of sedimentary 335 features on alluvial fans, Planet. Space Sci., 58(4), 482-508, 336 doi:10.1016/j.pss.2009.08.012.

337 Harrison, T. N., M. C. Malin, and K. S. Edgett (2009), Present-day gully activity 
observed by the Mars Reconnaissance Orbiter (MRO) Context Camera (CTX), in Bulletin of the American Astronomical Society, DPS Meeting \#41, p. 1113.

340 Heldmann, J. L., and M. T. Mellon (2004), Observations of martian gullies and

341 constraints on potential formation mechanisms, Icarus, 168(2), 285-304,

342 doi:10.1016/j.icarus.2003.11.024.

343 Hugenholtz, C. H. (2008), Frosted granular flow: A new hypothesis for mass wasting in 344 martian gullies, Icarus, 197, 65-72, doi:10.1016/j.icarus.2008.04.010.

345 Jakosky, B. M. (1986), On the thermal properties of Martian fines, Icarus, 66, 117-124, 346 doi:10.1016/0019-1035(86)90011-4.

347 Kinch, K. M., J. F. Bell III, W. Goetz, J. R. Johnson, J. Joseph, M. B. Madsen, and J. 348 Sohl-Dickstein (2015), Dust deposition on the decks of the Mars Exploration 349 Rovers: 10 years of dust dynamics on the Panoramic Camera calibration targets, $350 \quad$ Earth Sp. Sci., 2, 144-172, doi:10.1002/2014EA000073.

351 Kolb, K. J., A. S. Mcewen, and J. D. Pelletier (2010), Investigating gully flow 352 emplacement mechanisms using apex slopes, Icarus, 208, 132-142, 353 doi:10.1016/j.icarus.2010.01.007.

354 Lanza, N. L., G. A. Meyer, C. H. Okubo, H. E. Newsom, and R. C. Wiens (2010), 355 Evidence for debris flow gully formation initiated by shallow subsurface water on 356 Mars, Icarus, 205(1), 103-112, doi:10.1016/j.icarus.2009.04.014.

357 Lanza, N. L., H. E. Newsom, and M. M. Osterloo (2011), The systematic effects of 358 martian gravity on hillslope materials and mass movement processes, 42nd Lunar $359 \quad$ Planet. Sci. Conf., abstract \#2383. 
360 Levy, J. S., J. W. Head, J. L. Dickson, C. I. Fassett, G. A. Morgan, and S. C. Schon

361 (2010), Identification of gully debris flow deposits in Protonilus Mensae, Mars:

362 Characterization of a water-bearing, energetic gully-forming process, Earth Planet.

363 Sci. Lett., 294, 368-377, doi:10.1016/j.eps1.2009.08.002.

364 Luckman, B. H. (1992), Debris flows and snow avalanche landforms in the Lairig Ghru,

365 Cairngorm Mountains, Scotland, Geogr. Ann. Ser. A-PHYSICAL Geogr., 74(2/3), $366 \quad 109-121$.

367 Malin, M. C., and K. S. Edgett (2000), Evidence for recent groundwater seepage and 368 surface runoff on Mars, Science, 288(5475), 2330-2335,

369 doi:10.1126/science.288.5475.2330.

370 Malin, M. C., K. S. Edgett, L. V Posiolova, S. M. Mccolley, and E. Z. N. Dobrea (2006),

371 Present-day impact cratering rate and contemporary gully activity on Mars, Science, $372 \quad 314(5805), 1573-1577$.

373 Malin, M. C. et al. (2007), Context Camera Investigation on board the Mars

374 Reconnaissance Orbiter, J. Geophys. Res., 112(E5), E05S04,

375 doi:10.1029/2006JE002808.

376 Matmon, A., K. Nichols, and R. Finkel (2006), Isotopic insights into smoothening of

377 abandoned fan surfaces, Southern California, Quat. Res., 66, 109-118,

378 doi:10.1016/j.yqres.2006.02.010.

379 McEwen, A. S. et al. (2007), Mars Reconnaissance Orbiter's High Resolution Imaging

380 Science Experiment (HiRISE), J. Geophys. Res., 112(E5), E05S02,

381 doi:10.1029/2005JE002605. 
382 Neugebauer, G., G. Münch, H. H. Kieffer, S. C. Case Jr., and E. Miner (1971), Mariner

3831969 infrared radiometer results: Temperatures and thermal properties of the

384 Martian surface, Astron. J., 76(8), 719-749.

385 Okubo, C. H., L. L. Tornabene, and N. L. Lanza (2011), Constraints on mechanisms for

386 the growth of gully alcoves in Gasa crater, Mars, from two-dimensional stability

387 assessments of rock slopes, Icarus, 211(1), 207-221,

388 doi:10.1016/j.icarus.2010.09.025.

389 Presley, M. A., and P. R. Christensen (1997a), Thermal conductivity measurements of

390 particulate materials 1. A Review, J. Geophys. Res., 102(E3), 6535-6549,

391 doi:10.1029/96JE03303.

392 Presley, M. A., and P. R. Christensen (1997b), Thermal conductivity measurements of

393 particulate materials 2. Results, J. Geophys. Res., 102(E3), 6551-6566.

394 Reiss, D., S. van Gasselt, G. Neukum, and R. Jaumann (2004), Absolute dune ages and

395 implications for the time of formation of gullies in Nirgal Vallis, Mars, J. Geophys.

396 Res. E Planets, 109(6), 1-9, doi:10.1029/2004JE002251.

397 Schon, S. C., and J. W. Head (2012), Gasa impact crater, Mars: Very young gullies

398 formed from impact into latitude-dependent mantle and debris-covered glacier

399 deposits?, Icarus, 218(1), 459-477, doi:10.1016/j.icarus.2012.01.002.

400 Schon, S. C., J. W. Head, and C. I. Fassett (2009), Unique chronostratigraphic marker in 401 depositional fan stratigraphy on Mars: Evidence for ca. 1.25 Ma gully activity and 402 surficial meltwater origin, Geology, 37(3), 207-210, doi:10.1130/G25398A.1.

403 Thomas, N. et al. (2014), The Colour and Stereo Surface Imaging System (CaSSIS) for 

\#1067, Pasadena, CA.

406 Tornabene, L. L., J. E. Moersch, H. Y. McSween, A. S. McEwen, J. L. Piatek, K. A.

407 Milam, and P. R. Christensen (2006), Identification of large (2-10 km) rayed craters

408 on Mars in THEMIS thermal infrared images: Implications for possible Martian

409 meteorite source regions, J. Geophys. Res. E Planets, 111(10), 1-25,

410 doi:10.1029/2005JE002600.

411 Tornabene, L. L., G. R. Osinski, A. S. McEwen, J. M. Boyce, V. J. Bray, C. M. Caudill, J.

412 A. Grant, C. W. Hamilton, S. Mattson, and P. J. Mouginis-Mark (2012), Widespread

413 crater-related pitted materials on Mars: Further evidence for the role of target

414 volatiles during the impact process, Icarus, 220(2), 348-368,

415 doi:10.1016/j.icarus.2012.05.022.

416 Tornabene, L. L., J. L. Piatek, K. T. Hansen, S. J. Hutchinson, N. G. Barlow, G. R.

417 Osinski, S. J. Robbins, and A. S. McEwen (2016), Visible and thermophysical

418 characteristics of the best-preserved martian craters, part 1: Detailed morphological

419 mapping of Resen and Noord, 47th Lunar Planet. Sci. Conf., abstract \#2879.

420 Treiman, A. H. (2003), Geologic settings of Martian gullies: Implications for their origins,

$421 \quad$ J. Geophys. Res., 108(E4), 8031, doi:10.1029/2002JE001900.

422 Wechsler, A., and P. Glaser (1965), Pressure effects on postulated lunar materials, Icarus, 423 4, 335-352, doi:10.1016/0019-1035(65)90038-2.

424 Wechsler, A. E., P. E. Glaser, and J. A. Fountain (1972), Thermal properties of 425 granulated materials, in Thermal Characteristics of the Moon, Prog. Astron. 
428 Figure 1. (A) Subframe of CTX G06_020661_1440_XN_36S230W covering Gasa Crater

429 and Cilaos Crater, within which it lies. Blue and red lines mark the MOLA elevation

430 transects in B. North is up. (B) MOLA elevation profiles across Cilaos and Gasa Craters

431 (blue line) and only across Cilaos Crater (red line).

432 Figure 2. Example of younger (stratigraphically higher) and older (underlying) lobes

433 within an individual gully fan in Gasa Crater. Yellow box in A shows context for B. Note

434 the rough surface texture of the younger lobe compared to the underlying older portion of 435 the fan. Subframes of HiRISE ESP_014081_1440.

436 Figure 3. (A) CTX G06_020661_1440_XN_36S230W with THEMIS-derived thermal

437 inertia overlaid atop it, centred at $35.7^{\circ} \mathrm{S}, 129.4^{\circ} \mathrm{E}$, showing Gasa and Cilaos craters. (B)

438 Closer view of Gasa as marked by the white box in A. Numbered gullies indicate

439 locations of activity documented by Dundas et al. [2010, 2012, 2015]. Dots indicate each

440 documented gully (numbered clockwise from the eastern wall from 1-28; individual

441 numbers omitted for space).

442 Figure 4. (A) Polygons denoting areas sampled for thermal inertia values of gully/talus

443 aprons (white), alcoves (teal), and the entire wall (alcoves and aprons, dotted black).

444 Yellow polygon on the crater floor denotes pitted material. (B) Fan segments for gullies

445 (blues) and talus slopes (purples) and corresponding thermal inertia ranges. Basemap for

446 both A and B is a mosaic of subframes of CTX G06_020661_1440_XN_36S230W and

447 HiRISE ESP_014081_1440 and ESP_039531_1440. 
448 Figure 5. Mean thermal inertia values for the 66 mapped gully fan segments in Gasa

449 Crater with standard errors shown. Dot colours correspond to the legend in Figure 4B.

450 Fans were numbered clockwise from the western wall of the crater.

451 Figure 6. HiRISE IRB colour of gullied wall (B) and talus on slopes from mass wasting

452 (C). (A) CTX G06_020661_1440_XN_36S230W with HiRISE ESP_020661_1440

453 overlaid for context. White boxes denote the locations of $\mathrm{B}$ and $\mathrm{C}$, with $\mathrm{C}$ rotated $180^{\circ}$

454 for easier comparison to B. White arrow in B denotes a new gully flow in Gasa

455 documented by Dundas et al. [2012], formed in Mars Year 30 between Ls 109-152.

456 Note its blue appearance compared to the surrounding fan deposits. 
Table 1. Average thermal inertia (in TIU) of gullied (N) and non-gullied (SW and SE) walls in Gasa Crater

\begin{tabular}{|c|c|c|c|c|c|c|c|c|c|c|c|c|}
\hline \multirow[b]{2}{*}{ Segment } & \multicolumn{4}{|c|}{ Gullied Wall (N) } & \multicolumn{4}{|c|}{ Non-Gullied Wall (SW) } & \multicolumn{4}{|c|}{ Non-Gullied Wall (SE) } \\
\hline & $\begin{array}{l}\text { Mean } \\
\text { [Std } \\
\text { Error] }\end{array}$ & Max & Min & $\begin{array}{l}\text { Std } \\
\text { Dev }\end{array}$ & $\begin{array}{l}\text { Mean } \\
\text { [Std } \\
\text { Error] }\end{array}$ & Max & Min & $\begin{array}{l}\text { Std } \\
\text { Dev }\end{array}$ & $\begin{array}{l}\text { Mean } \\
\text { [Std } \\
\text { Error] }\end{array}$ & Max & Min & $\begin{array}{l}\text { Std } \\
\text { Dev }\end{array}$ \\
\hline Aprons & $\begin{array}{r}379 \\
{[2]}\end{array}$ & 574 & 280 & 45 & $\begin{array}{r}454 \\
{[2]}\end{array}$ & 537 & 357 & 30 & $\begin{array}{r}436 \\
{[4]}\end{array}$ & 607 & 324 & 54 \\
\hline Alcoves $^{\dagger}$ & $\begin{array}{r}470 \\
{[3]}\end{array}$ & 720 & 336 & 71 & $\begin{array}{r}502 \\
{[5]}\end{array}$ & 722 & 351 & 61 & & & & \\
\hline $\begin{array}{l}\text { Entire } \\
\text { Wall }\end{array}$ & $\begin{array}{r}418 \\
{[2]}\end{array}$ & 720 & 275 & 74 & $\begin{array}{r}482 \\
{[3]}\end{array}$ & 722 & 357 & 52 & $\begin{array}{r}433 \\
{[4]}\end{array}$ & 607 & 324 & 54 \\
\hline
\end{tabular}

The SE wall of the crater hosts no alcoves. 

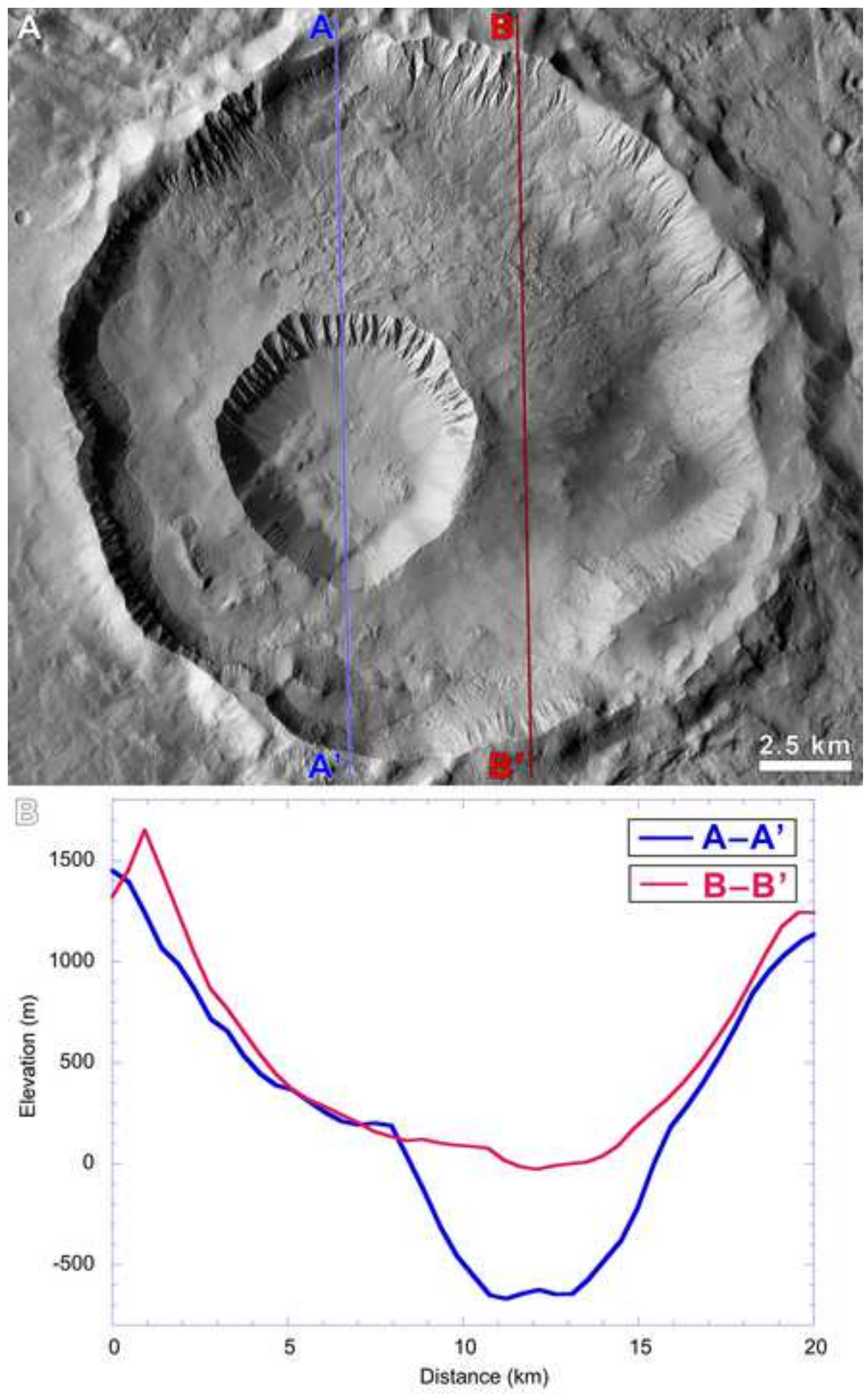

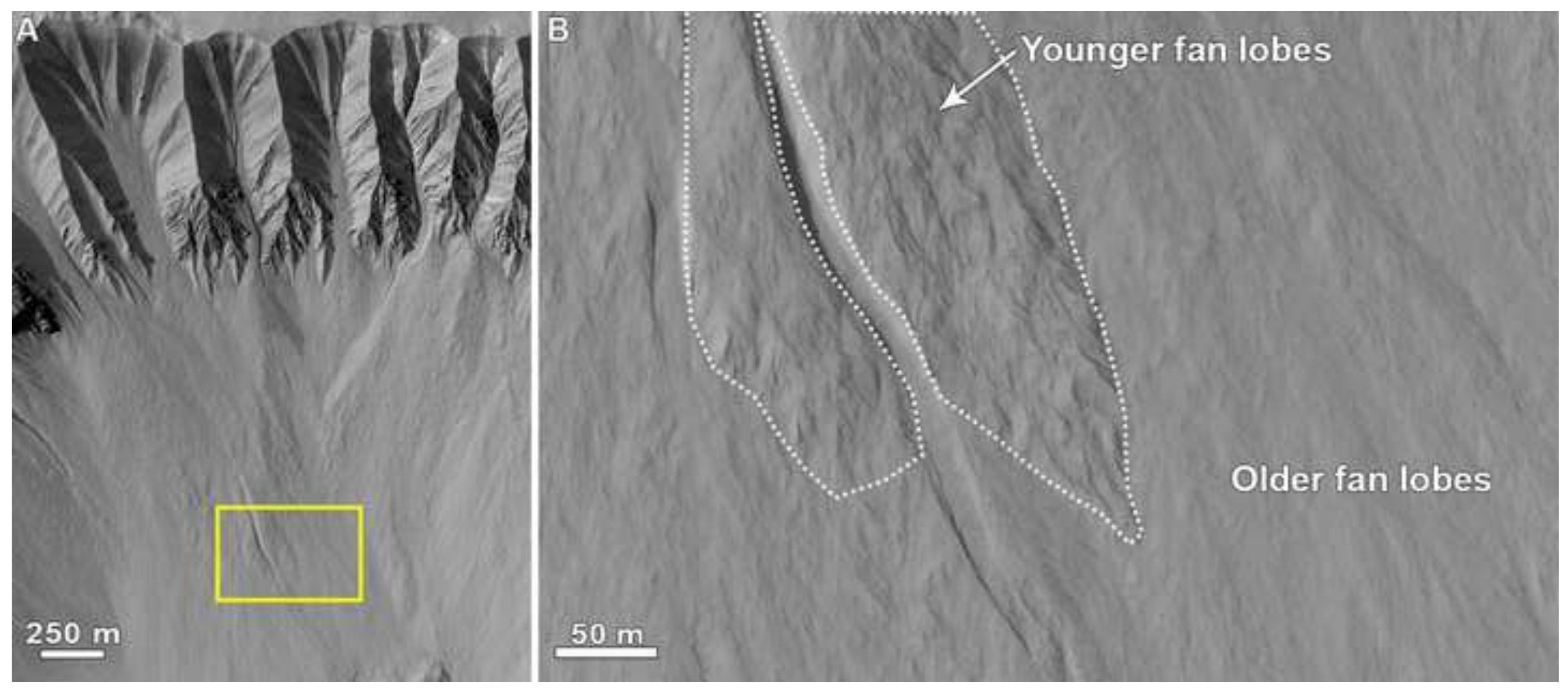

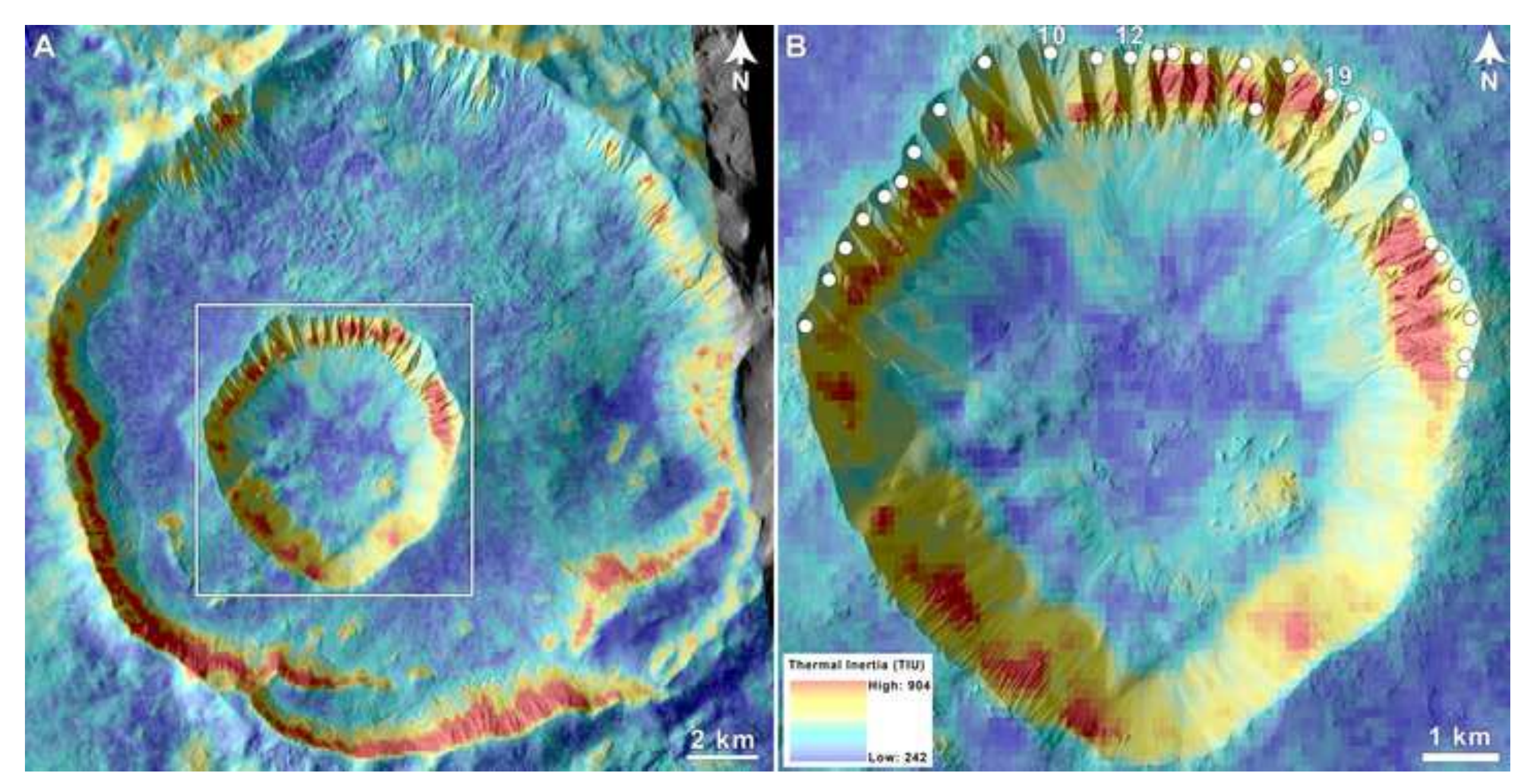

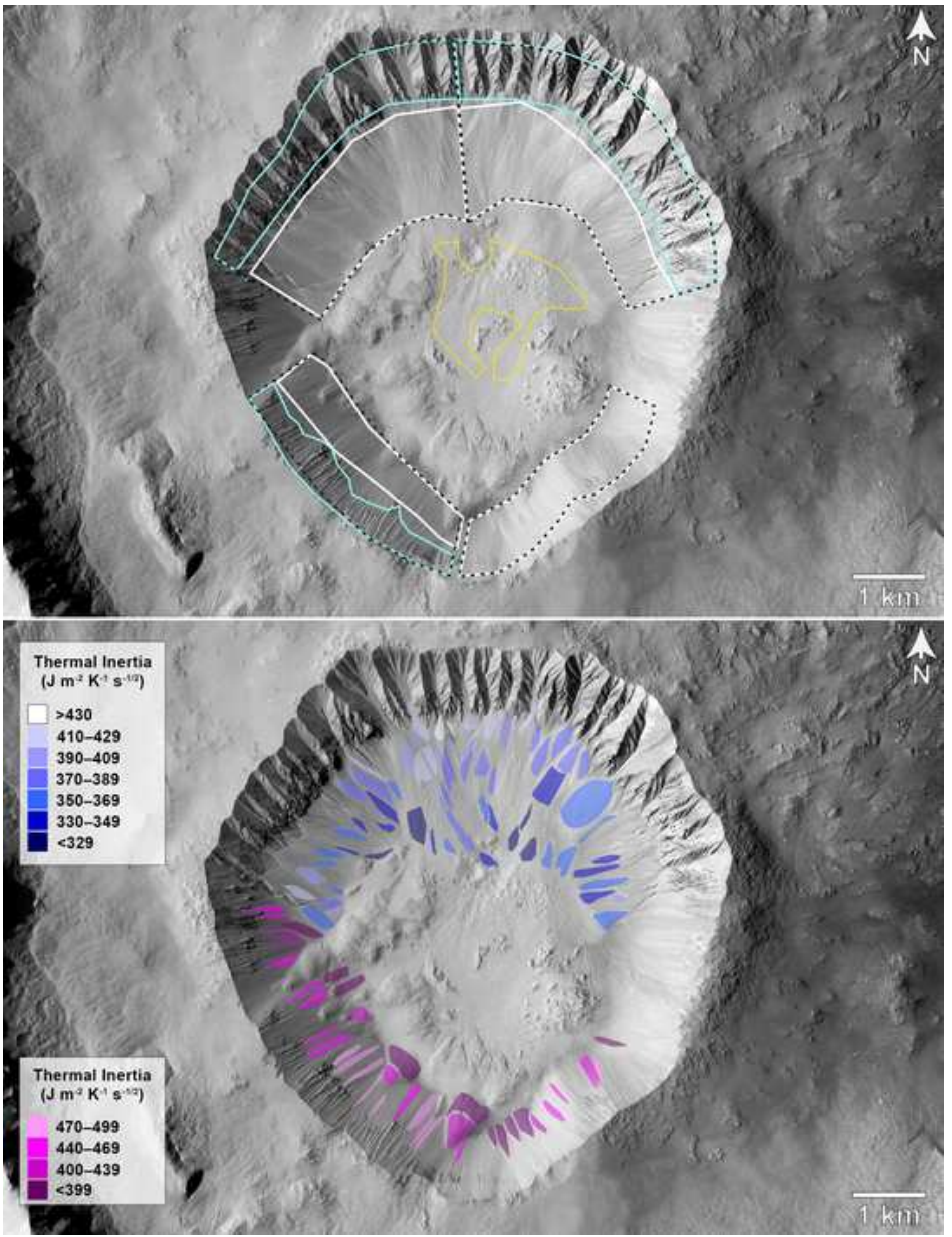


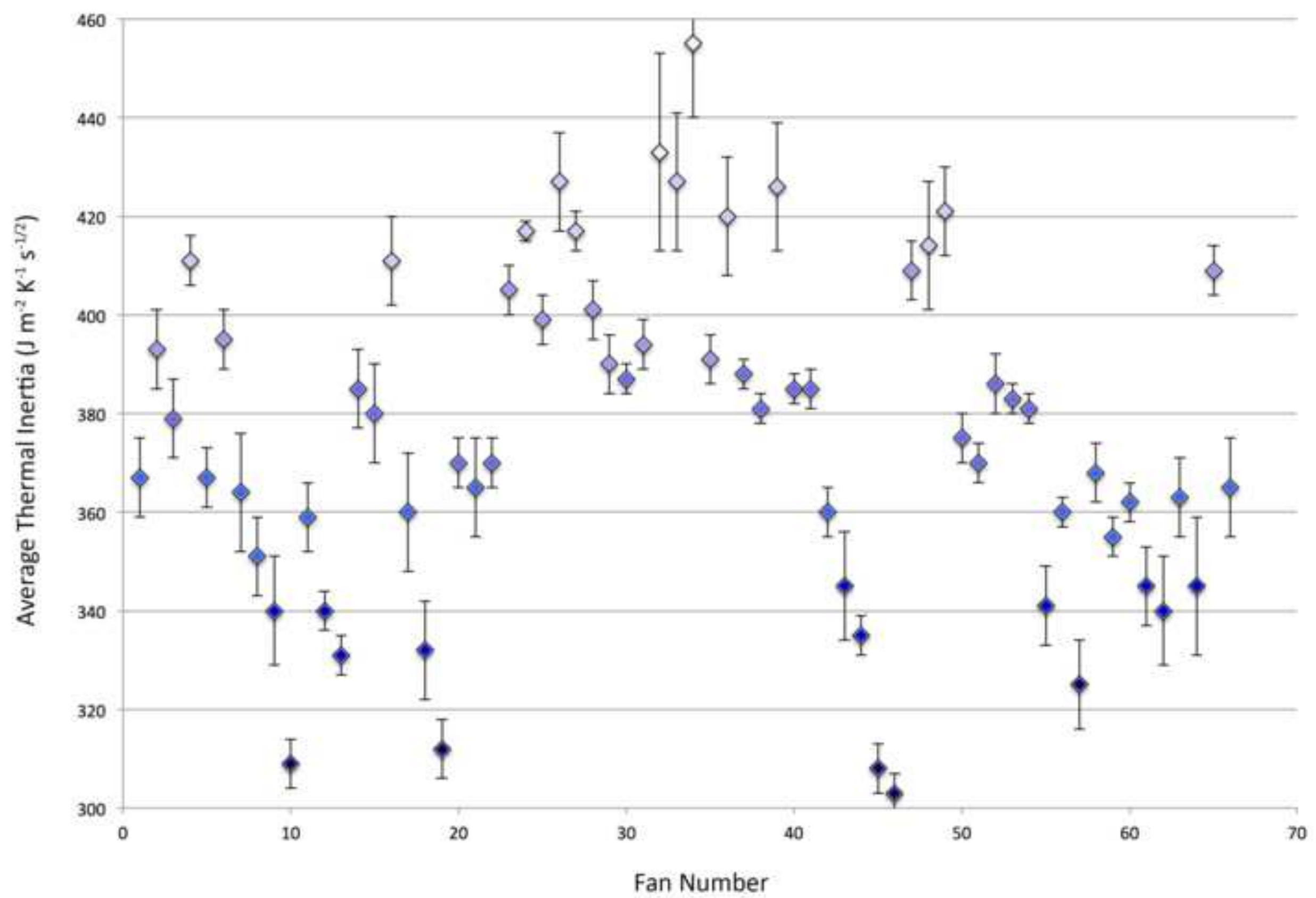



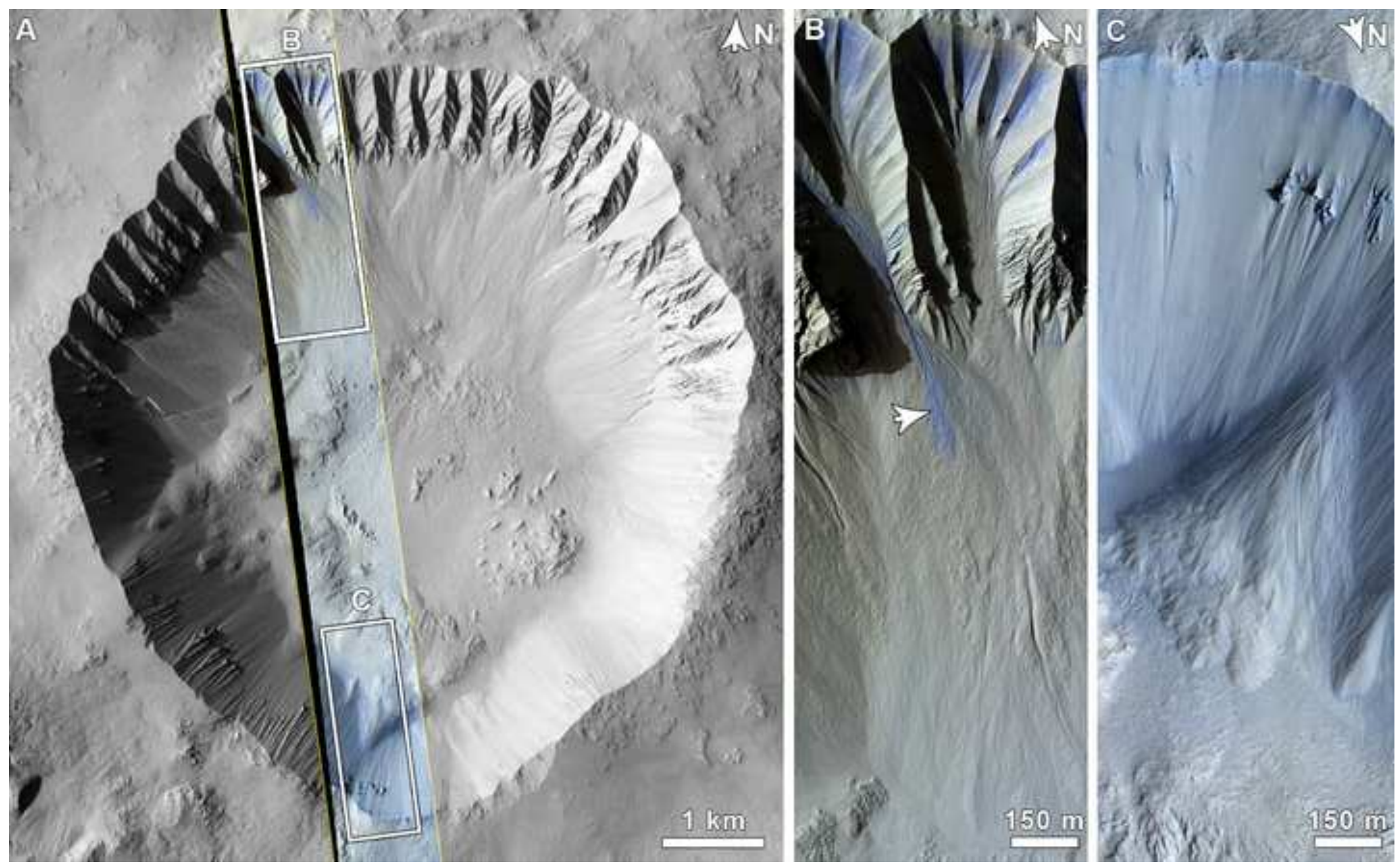